Stela Márcia Pereira

Elaine Pereira da Silva

Tagliaferro

Karine Laura Cortellazzi

Gláucia Maria Bovi Ambrosano

Fábio Luiz Mialhe

Marcelo de Castro Meneghim

Antonio Carlos Pereira

\section{Estimate of DMFT index using teeth most affected by dental caries in twelve-year-old children}

\section{Estimativa do Índice CPOD usando os dentes mais afetados pela cárie dentária aos doze anos}

\begin{abstract}
The objective of the study was to develop regression models to describe the epidemiological profile of dental caries in 12-year-old children in an area of low prevalence of caries. Two distinct random probabilistic samples of schoolchildren $(n=1,763)$ attending public and private schools in Piracicaba, Southeastern Brazil, were studied. Regression models were estimated as a function of the most affected teeth using data collected in 2005 and were validated using a 2001 database. The mean (SD) DMFT index was 1.7 (2.08) in 2001 and the regression equations estimated a DMFT index of 1.67 (1.98), which corresponds to $98.2 \%$ of the DMFT index in 2001 . The study provided detailed data on the caries profile in 12-year-old children by using an updated analytical approach. Regression models can be an accurate and feasible method that can provide valuable information for the planning and evaluation of oral health services.
\end{abstract}

DESCRIPTORS: Child. Dental Caries. DMF Index. Oral Health.

\section{RESUMO}

O objetivo do estudo foi desenvolver modelos de regressão para delinear o perfil epidemiológico da cárie dentária em localidade com baixa prevalência de cárie aos 12 anos de idade. Foram examinadas duas amostras probabilísticas ( $\mathrm{n}=1.763$ ) de indivíduos de escolas públicas e privadas de Piracicaba,(SP). Dados sobre os dentes mais afetados foram coletados em 2005 e validados utilizando um banco de dados (2001). A média (dp) do CPOD foi de 1,7 $(2,08)$ em 2001 e os modelos de regressão desenvolvidos estimaram um CPOD de 1,67 (1,98) em 2005, o qual representa 98,2\% do CPOD em 2001. Os resultados apresentaram detalhes do perfil da cárie dentária aos 12 anos, usando uma abordagem analítica atual. Os modelos de regressão poderiam ser considerados como uma forma acurada e factível no auxílio do planejamento e avaliação dos serviços em saúde bucal.

DESCRITORES: Criança. Cárie Dentária. Índice CPO. Saúde Bucal. 


\section{INTRODUCTION}

Data on dental health in 12-year-old children have been published worldwide, showing both a trend towards decline in caries experience and unequal distribution of the disease. ${ }^{1}$

Studies conducted as early as the $1940 \mathrm{~s}^{4}$ showed that some teeth are more frequently affected by caries than others. Although the teeth most affected by dental caries at present are practically the same as those 60 years ago, e.g. the first permanent molars, the epidemiological profile of the disease has completely changed. In the 1940s almost all individuals had caries experience while nowadays the highest caries scores are concentrated in a small number of individuals, ${ }^{4}$ the so-called "polarization group". Thus, many questions arise about what the actual epidemiological profile of dental caries would be; how the disease is distributed among the population; and what risk factors are associated. This demands the search for tools that would give a more accurate disease distribution profile. The reduction in caries prevalence has been an ongoing process for years, and has brought about changes in the epidemiological profile of the disease, especially the concentration of lesions on specific surfaces/teeth. ${ }^{2}$

The present study aimed to develop regression models to describe the epidemiological profile of dental caries in 12year-old children in an area of low caries prevalence.

\section{METHODS}

The sample size included 1,763 12-year-old schoolchildren attending private and public schools in 2001 $(\mathrm{n}=824)$ and in $2005(\mathrm{n}=939)$ in the city of Piracicaba, Southeastern Brazil. The schools were selected by cluster sampling techniques from official records provided by the Local Department of Education.

Dental examinations were performed by two dentists who were previously trained and calibrated by a "gold standard". The intra-examiner reproducibility in both the pilot phase and main surveys was assessed by kappa statistics, and was higher than 0.91 . The subjects were examined in an outdoor setting, under natural light, after previous tooth brushing supervised by a dental hygienist and air-drying, with plane mouth mirror and CPI probe (ball point), following the World Health Organization (WHO) recommendations. ${ }^{5}$ Duplicate examinations were also conducted in $10 \%$ of the sample throughout the study, and intra-examiner reliability was good (kappa >0.91).

The DMFT distribution (absolute frequency, cumulative absolute frequency and cumulative relative frequency) was calculated as a function of each permanent tooth in 2001 and 2005 separately to identify the teeth most affected by caries.
The regression models were constructed using only the 2005 data and were estimated as a function of the most affected teeth (MODEL phase). Regression models were then validated (validation phase) using the second database (2001 data).

The mean number of decayed, missing and filled teeth obtained in the regression models was the estimated DMFT. Finally, the paired t-test was used for comparison between real DMFT and estimated DMFT. All statistical tests were performed using the SAS software (SAS Institute Inc. 8.2, 2001).

The study was conducted following the Declaration of Helsinki and was approved by the Research Ethics Committee (protocols \#31/2000; \#148/2003) of the Faculty of Dentistry of Piracicaba (UNICAMP).

\section{RESULTS}

The DMFT distribution showed that the first permanent molars (teeth 46, 36, 16 and 26) were the teeth most affected by caries in both surveys (2001 and 2005), followed by the mandibular second permanent molars (teeth 37 and 47). Moreover, it was verified that the sequence of the most affected teeth was the same in both surveys, and also that the absolute frequency, cumulative absolute frequency, and cumulative relative frequency were also similar in 2001 and 2005.

The Table shows the regression equations as a function of the most affected teeth, starting with the most affected tooth using the 2005 data (MODEL). Thus, the first equation included tooth 46 , which was the most affected; the second equation included teeth $46+36$, and so on, successively. It was verified that $50 \%$ of the DMFT variation $\left(\mathrm{R}^{2}\right.$, coefficient of determination) was attributed to tooth 46 , while $78 \%$ was attributed to first permanent molars.

According to the Table, while the real DMFT was 1.7, the estimated DMFT using teeth $46+36+16+26$ was 1.67 in 2001, which corresponds to $98.2 \%$ of the real DMFT. The estimated DMFT using teeth $46+36$, $46+36+16,46+36+16+26,46+36+16+26+37$ and $46+36+16+26+37+47$ did not differ statistically from the real DMFT $(\mathrm{p}>0.1)$. However, by using only the first molars (teeth most affected by dental caries), it was evidenced that the adjustment of the model was very good $\left(R^{2}=0.78\right)$.

Considering the estimates provided by the equations using first molars, the test power was higher than 0.99. In other words, the probability of rejecting the null hypothesis $\left(\mathrm{H}_{0}\right.$ : estimated average $=$ observed average) and to make a mistake was lower than 0.01 and the difference between the means (estimated and observed) was 0.03 . Therefore, the equation provided a good average estimate. 
Table. Regression models in function of the most affected teeth in 2005 and mean (SD) estimated DMFT obtained in the regression models using the 2001 database. Piracicaba, Southeastern Brazil.

\begin{tabular}{|c|c|c|c|}
\hline \multirow{2}{*}{ Teeth } & \multirow{2}{*}{ Regression models $\left(\mathrm{R}^{2}\right)$} & \multicolumn{2}{|c|}{ Estimated DMFT } \\
\hline & & Mean $(\mathrm{SD}) * * * *$ & $95 \% \mathrm{Cl}$ \\
\hline 46 & $\mathrm{Y}=0.41077+2.94214 \times$ DMFT $1 *\left(0.5015^{* *}\right) * * *$ & $1.23(1.48)$ & $1.13 ; 1.31$ \\
\hline $46+36$ & $\mathrm{Y}=0.21207+1.81307 x$ DMFT $2\left(0.6221^{* *}\right) * * *$ & $1.60(1.80)$ & $1.48 ; 1.71$ \\
\hline $46+36+16$ & $\mathrm{Y}=0.07566+1.48601 \times \mathrm{DMFT} 3\left(0.7388^{* *}\right)^{* * *}$ & $1.62(1.68)$ & $1.51 ; 1.72$ \\
\hline $46+36+16+26$ & $\mathrm{Y}=0.03627+1.21535 \times \mathrm{DMFT} 4\left(0.7841^{* *}\right) * * *$ & $1.67(1.98)$ & $1.53 ; 1.80$ \\
\hline $46+36+16+26+37$ & $\mathrm{Y}=0.00491+1.19902 \times \mathrm{DMFT} 5\left(0.8292^{* *}\right) * * *$ & $1.74(2.05)$ & $1.60 ; 1.85$ \\
\hline $46+36+16+26+37+47$ & $\mathrm{Y}=0.00459+1.16527 \times$ DMFT $6(0.8553 * *) * * *$ & $1.81(2.14)^{* * *}$ & $1.67 ; 1.93$ \\
\hline $46+36+16+26+37+47+14$ & $\mathrm{Y}=0.00137+1.114857 \times$ DMFT $7(0.8734 * *) * * *$ & $1.73(2.08)$ & $1.60 ; 1.85$ \\
\hline
\end{tabular}

$*$ The second column shows the regression equations including mean DMFT of the teeth in the first column (DMFT $1=$ total MFT of tooth 46; DMFT 2 = total DMFT of teeth 46 and 36; DMFT 3 - 7 successively)

$* * \mathrm{R}^{2}$ (coefficient of determination)

$* * * \mathrm{p}<0.0001$

**** The third column shows a comparison of estimated DMFT (by means of regression equations) and real DMFT (mean 1.70; standard deviation 2.08) using paired t-test.

\section{DISCUSSION}

As the disease levels have declined, two facts have been evidenced: the non-normal distribution of dental caries and the concentration of these lesions in some individuals (polarization) and specific teeth. ${ }^{2,3}$ The nonnormality of the data relating to dental caries was the authors' focus of attention; however, the sample size was large ( $n=939$ in 2005 and $n=824$ in 2001), and in spite of violating the supposition of normality, an adequate model was constructed for estimating mean DMFT in a population with low prevalence of caries and good quality of adjustment $\left(\mathrm{R}^{2}=0.7841\right)$.

Moreover, the estimated validity of regressions was performed in a second sample. The proof of estimated validity data was verified using a database (2001) with low prevalence of caries, too. The mean real DMFT was 1.7 (confidence interval: $1.56 ; 1.84$ ) and the estimated DMFT was 1.67 (confidence interval: 1.53;1.80), that identifies a difference of only 0.03 .

The present study showed that the first permanent molars were the preferred site of most lesions, concentrating $82 \%$ and $81.5 \%$ of the real DMFT observed in 2001 and 2005, respectively. In regard to regression equations, when the first permanent molars were included, the estimated DMFT was 1.67, which did not differ statistically ( $p=0.4683$ ) from the real DMFT (1.7). The regression equations showed a good adjustment $\left(\mathrm{R}^{2}=0.78\right)$, these findings can be supported by the fact that $78 \%$ of the DMFT variation in 2005 can be attributed to the first permanent molars (Table). The great variation of the DMFT index could be explained by some teeth (teeth 16, 26, 36 and 46), and no significant increment was seen after the inclusion of other teeth. The use of these teeth was sufficient for estimating the DMFT index in 12-year-old children.
The present study showed that these formulas could be useful in studies of larger samples in areas with low prevalence of caries, as they can provide input to support oral health service planning and monitoring. In addition, it is believed that time for data collection on dental caries will be reduced by limiting it to examinations of the most affected teeth (e.g., first molars) and, consequently, it could both save time and money, thus optimizing dental health surveys.

Considering the hypothesis that if the prevalence of caries were concentrated in some individuals (polarization), and not in a specific case, particularly in some teeth, one could assume that by knowing the estimate of caries prevalence in a municipality, local health authorities could better evaluate the use of preventive measures and their cost-effectiveness ratio in large samples.

Although the study results are reliable, as shown by the validation phase data, the regression equations were, however, constructed using data from a large sample with low prevalence of caries. Therefore, further studies should be conducted in areas/samples with moderate and high DMFT to assess the validity and applicability of the equations. Since the study was limited to 12-year-old children, the regression models cannot be applicable to children of all ages. Moreover, in spite of the results about caries distribution being a common approach in this type of study, they confirm the disease distribution previously seen in Brazil and elsewhere. On the other hand, by using an updated analytical approach, the present study was able to describe the current epidemiological profile of the disease, which is different from that seen decades ago.

In conclusion the present study provided details on the caries profile in 12-year-old children by using an updated analytical approach. Regression models can be an accurate and feasible method to provide valuable information for the planning and evaluation of oral health services. 


\section{REFERENCES}

1. Antunes JLF, Narvai PC, Nugent ZJ. Measuring inequalities in the distribution of dental caries. Community Dent Oral Epidemiol. 2004;32(1):41-8. DOI: 10.1111/j.1600-0528.2004.00125.x

2. Batchelor PA, Sheiham A. Grouping of tooth surfaces by susceptibility to caries: a study in 5-16 yearold children. BMC Oral Health. 2004;4(1):2. DOI: 10.1186/1472-6831-4-2
3. Bratthall D. Introducing the Significant Caries Index together with a proposal for a new global oral health goal for 12-year-olds. Int Dent J. 2000;50(6):378-84.

4. Klein H, Palmer CE. Studies on dental caries $\mathrm{x}$ : a procedure for the recording and statistical processing of dental examination findings. I Dent Res. 1940;19(3):243-56.

5. World Health Organization. Oral health surveys basic methods. 4. ed. Geneva; 1997.

Pereira SM was supported by Fundação de Amparo à Pesquisa do Estado de São Paulo (FAPESP - grant 05/56699-6; master's scholarship).

Article based on the dissertation by Pereira SM presented to Faculdade de Odontologia de Piracicaba UNICAMP, in 2006 Presented as poster at European Organisation for Caries Research (ORCA), Denmark, May 2007. 